\title{
A RESTRIÇÃO DO USO MEDICINAL DA CANNABIS SATIVA FACE AO PRINCÍPIO DA AUTONOMIA DA VONTADE
}

\author{
THE RESTRICTION OF THE MEDICINAL USE OF CANNABIS SATIVA IN THE \\ FACE OF THE PRINCIPLE OF AUTONOMY OF THE WILL
}

\section{LA RESTRICCIÓN DEL USO MEDICINAL DE LA CANNABIS SATIVA FRENTE AL PRINCIPIO DE LA AUTONOMIA DE LA VOLUNTAD}

MARGARETH Vetis ZAGANELLI

http://orcid.org/0000-0002-8405-1838 / http://lattes.cnpq.br/3009983939185029 / mvetis@terra.com.br

Doutora em Direito (UFMG). Professora Titular da Universidade Federal do Espírito Santo (UFES). Docente permanente no Programa de Pós-Graduação em Gestão Pública da Universidade Federal do Espírito Santo (UFES). Coordenadora do Grupo de Pesquisa Bioethik (UFES) e do Grupo de Pesquisa Direito e Ficção (UFES). Vitória, ES,

Brasil.

\section{JoÃo Victor GOMES CORREIA}

http://orcid.org/0000-0002-7763-7689 / http://lattes.cnpq.br/5909110418024271 / jvgomesc@gmail.com

Acadêmico do curso Direito pela Universidade Federal do Espírito Santo (UFES). Participante do projeto de extensão da Liga Universitária do Direito da UFES. Pesquisador do grupo de estudos Bioetik. Vitória, ES, Brasil.

\begin{abstract}
RESUMO
O presente trabalho aborda a restrição do uso medicinal da Cannabis sativa no Brasil, contrapondo aos aspectos teóricos e legais do princípio da autonomia da vontade na perspectiva da Bioética. Por meio de metodologia exploratória de natureza qualitativa, mediante utilização de investigação bibliográfica, faz-se uma revisão das literaturas acadêmicas e dos dados fornecidos pelos órgãos estatais e meios de comunicação, pesquisando como a legislação brasileira tem tratado o assunto e quais seriam os possíveis benefícios terapêuticos que os medicamentos derivados da planta podem trazer para determinadas enfermidades. A seguir, aborda-se as perspectivas nacionais e internacionais sobre o uso medicinal da Cannabis para se inferir, à luz do princípio da autonomia da vontade, os impactos gerados pelo impedimento dos tratamentos à base das propriedades terapêuticas da maconha.
\end{abstract}

Palavras-chave: Autonomia da vontade; Cannabis; Medicinal; Restrição; Bioética.

\begin{abstract}
The present work approaches the restriction of the medicinal use of Cannabis sativa in Brazil while opposing it to the theoretical and legal aspects of the principle of autonomy of the will in the perspective of Bioethics. Using an exploratory methodology that has a qualitative nature and bibliographical research, a review of the academic literatures and of the data provided by state organs and by the media is done, researching the way that the brazilian's legislation deals with the subject and what would be the possible therapeutic benefits that the plant-derived medicinal products could bring to treat certain diseases. Next, the national and international perspectives on the medicinal use of Cannabis are approached in order to infer, under the light of the principle of autonomy of the will, the impacts generated by the obstruction of the treatments based on the therapeutic properties of marijuana.
\end{abstract}

Keywords: Autonomy of the will; Cannabis; Medicinal; Restriction; Bioethics. 


\section{RESUMEN}

El trabajo se refiere a la restricción del uso medicinal del Cannabis sativa en el Brasil, contraponiendo con los aspectos teóricos y legales del principio de la autonomía de la voluntad en la perspectiva de la Bioética. Por medio de metodología exploratoria de naturaleza cualitativa, mediante utilización de investigación bibliográfica, se hace una revisión de las literaturas académicas y de los datos proporcionados por los órganos estatales y por los medios de comunicación, investigando la forma que la legislación brasileña trata el asunto y cuáles serían los posibles beneficios terapéuticos que los medicamentos derivados de la planta pueden traer a determinadas enfermedades. Después, se abordan las perspectivas nacionales e internacionales sobre el uso medicinal del Cannabis para inferir, a la luz del principio de la autonomía de la voluntad, los impactos generados por el impedimento de los tratamientos a base de las propiedades terapéuticas de la marihuana.

Palabras clave: Autonomía de la voluntad; Cannabis; Medicinal; Restricción; Bioética.

\section{SUMÁRIO}

INTRODUÇAO; 1 PRINCÍPIO DA AUTONOMIA; 2 CANNABIS: ASCEPÇÕES LEGAIS E TERAPÊUTICAS; 2.1 Restrições e tipificação penal do consumo; 2.2 Propriedades terapêuticas; 3 AUTONOMIA DA VONTADE VS RESTRIÇÃO DO USO MEDICINAL DA MACONHA; 4 O USO MEDICINAL DA CANNABIS NO CONTEXTO BRASILEIRO; 5 BREVE PANORAMA SOBRE O TRATAMENTO LEGAL DADO AO USO MEDICINAL DA MACONHA FORA DAS FRONTEIRAS NACIONAIS; REFERÊNCIAS.

\section{INTRODUÇÃO}

Vastos são os aspectos que a Bioética incide sobre o sistema do direito positivo, verificando-se que os dilemas e as inquietações desse campo de estudo se mostram presentes no cotidiano acadêmico. Do mesmo modo, os princípios da Bioética e do Biodireito acabam sendo norteadores de vários aspectos da ética médica, assim como pontos cruciais para a formação do arcabouço legal. Dentre tantos, o princípio da autonomia da vontade, ou simplesmente princípio da autonomia, é basilar para a interpretação de muitas realidades atuais.

No contexto contemporâneo tem se divulgado pesquisas científicas e experimentos laboratoriais com a Cannabis sativa $L$. ou a comumente conhecida maconha. 0 foco dos trabalhos tem sido nas propriedades benéficas que a planta pode proporcionar com a finalidade de tratamento para amenização de sintomas e controle de doenças de difícil resolução com as manobras clínicas convencionais. Mesmo assim, ainda se controverte a eficácia da maconha como meio farmacológico.

Contudo, tem se constatado nos últimos anos o avanço das pesquisas médicas sobre a Cannabis, tornando-a uma opção aos pacientes de inúmeras enfermidades severas. Todavia, essa possibilidade se resvala na proibição legal dado o caráter entorpecente que a planta ganha, ou seja, como bem se sabe a maconha está enquadrada como uma droga ilícita e seu uso se torna um incurso contra o ordenamento repressivo. 
Por via de consequência, a utilização da maconha para o uso medicinal é restringida pela proibição legal, sendo, que mesmo com tratamentos já cientificamente comprovados, os órgãos estatais ainda impedem o pleno acesso dos pacientes às intervenções médicas com a Cannabis.

Nesta esteira, propõe-se como objetivo central desse estudo uma averiguação do quanto a restrição do uso medicinal da maconha no Brasil violaria o princípio da autonomia. Mas vai além, coliga-se a análise principal a pontos convergentes que também sofrem interferência da restrição medicinal da Cannabis, juntamente com outros princípios e valores que abarcam a temática.

Subsidiando a questão principal, apresenta-se uma ideia orientadora do princípio da autonomia, como ponto necessário para discussão. Levanta-se os avanços clínicos e as ressalvas sobre o uso dos produtos e do consumo in natura à base da maconha para tratamento de determinadas doenças. E, completando a discussão, descreve-se e se analisa, à luz do presente debate, os casos brasileiros que tangenciam o assunto e as experiências fora das fronteiras nacionais que ajudam a propor soluções para os impasses existentes.

Tal enfoque se justifica, pois, recentemente, as propriedades terapêuticas da planta têm tomado os telejornais e a indústria cinematográfica, bem como sendo alvo de discussão nas instâncias governamentais e judiciais. Por isso, a necessidade de uma análise sob enfoque da Bioética e do Biodireito sobre essa problemática ainda em curso. Abre-se questionamentos como: Até que ponto a restrição fere o direito do paciente se tratar? Como a restrição a afeta a possibilidade de uma vida digna? Uma vez comprovada a eficácia dos medicamentos, o que impede a abertura para aquisição? Como são resolvidas essas questões em países diferentes e qual experiência pode auxiliar o Brasil? Essas e outras indagações são discorridas e debatidas no texto, mas também abertas para análises posteriores.

Desse modo, o presente trabalho analisa a restrição do uso medicinal da Cannabis e o seu impacto para a efetividade do princípio da autonomia da vontade. Para tanto, utiliza-se metodologia exploratória investigando qualitativamente as bibliografias já dispostas e os dados fornecidos pelos órgãos estatais e organizações de interesse comum. Após apresentar os aspectos teóricos do princípio da autonomia da vontade e as necessárias considerações, no âmbito terapêutico e legal, da Cannabis sativa, aborda-se o contraponto proposto como objeto de investigação e por derradeiro expõe-se as perspectivas nacionais e internacionais do uso medicinal da maconha. 


\section{PRINCÍPIO DA AUTONOMIA DA VONTADE}

Para se chegar à pretensão do trabalho é preciso retomar as ideias de autonomia na Bioética e no Biodireito. Na toada deste estudo, faz-se uma análise lato da autonomia da vontade destinando tal princípio para os pacientes que necessitam de determinado tratamento, direcionando, assim, as conceituações para o objetivo da pesquisa.

Considerado como um dos princípios basilares a partir da obra de Beauchamp e Childress que tinham como base o relatório de Belmont ${ }^{1}$, o princípio da autonomia foi tecido ao longo do tempo para se chegar à ideia atual. A partir do pós-guerra a concepção de autodeterminação individual se calcarizou, como exemplifica o próprio Código de Nuremberg ${ }^{2}$. Assim, já na segunda metade do século XX, buscou-se a afirmação dos direitos fundamentais dos homens, os quais se incluem os direitos à individualidade e à saúde. Não obstante, no Brasil,

desde a década de 80 , códigos de ética profissional vêm tentando estabelecer uma relação dos profissionais com seus pacientes, na qual o princípio da autonomia tenda a ser ampliado. Em nosso país, cresce a discussão e a elaboração de normas deontológicas sobre as questões que envolvem as relações da assistência à saúde, contendo os direitos fundamentais que devem reger a vida do ser humano. ${ }^{3}$

Neste sentido, também houve uma construção conceitual para o entendimento de autonomia. Epistemologicamente, autonomia tem sua raiz no grego, autos (si mesmo) nomos (normas), ou seja, a autonomia pode ser entendida como normas próprias, aquilo que define para si como norma ou aquilo que o indivíduo determina como bom para si. ${ }^{4}$

Na concepção de Sá e Naves, o princípio da autonomia da vontade “pode ser entendido como o reconhecimento de que a pessoa possui capacidade para se autogovernar". 5 Sanllehí

\footnotetext{
1 DINIZ, Débora; GUILHEM, Dirce. O que é Bioética. São Paulo: Brasiliense, 2002. p. 25.

20 código consagra a ideia que se deve haver consentimento e capacidade de escolha para qualquer submissão de indivíduos a experimentos médicos. Cf. ONU. Organização das Nações Unidas. Código de Nuremberg. 1947.

${ }^{3}$ MUÑOZ, Daniel Romero; FORTES, Paulo Antonio Carvalho. O Princípio da Autonomia e o Consentimento Livre e Esclarecido. In: COSTA, Sérgio Ibiapina Ferreira; GARRAFA, Volnei; OSELKA, Gabriel. Iniciação à Bioética. [s.l]: Conselho Federal de Medicina, 1998. p. 57-58.

${ }^{4}$ Refletindo na questão médica, Maria Helena Diniz entende que se deve considerar "o paciente capaz de autogovernar-se, ou seja, de fazer suas opções e agir sob orientação dessas deliberações tomadas, devendo, por tal razão, ser tratado com autonomia." O estado atual do Biodireito. São Paulo: Saraiva, 2002, p. 15.

5 SÁ, Maria de Fátima Freire de; NAVES, Bruno Torquato de Oliveira. Manual de Biodireito. Belo Horizonte: del Rey, 2011. p. 34.
} 
entende a autonomia como "la libertad del querer o de la voluntad como el estado en que el proprio agente controla la concepción, deliberación y decisión de lo que hará". 6 Pensando na relação médico-paciente, Maria Helena Diniz coloca que “o princípio da autonomia requer que o profissional da saúde respeite a vontade do paciente, ou de seu representante, levando em conta, em certa medida, seus valores morais e crenças religiosas (...)" e continua, "considera o paciente capaz de autogovernar-se, ou seja, de fazer suas opções e agir sob orientação dessas deliberações tomadas, devendo, por tal razão, ser tratado com autonomia". ${ }^{7}$

Ao observar as conceituações doutrinárias da autonomia da vontade, percebe-se que o princípio se direciona ao indivíduo e aos terceiros. Para o primeiro, encontra-se a possibilidade da autodeterminação sobre as diretivas pessoais para a condução da vida, sempre com pleno entendimento do que se estar por fazer. Já para os segundos, deposita-se aos que estão no derredor a necessidade de respeito das escolhas individuais e na desobstrução das barreiras para as tomadas de decisões esclarecidas. Pensando especificamente na autonomia da vontade do paciente, compreende-se que ele, uma vez tendo consciência livre sobre os malefícios e os benefícios de determinado tratamento, deve ter livre escolha de submissão ou não à manobra médica proposta. Nessa toada, a vontade deve estar desembaraçada de coação interna ou externa que afetem o seu perfeito e real conteúdo. ${ }^{8}$

Diferentemente da vertente filosófica de $\mathrm{Kant}^{9}$, que determina que a autonomia é regulada apenas pela razão, a Bioética compreende que a autonomia se concretiza quando “existem elementos emocionais e racionais de opção, ou seja, se houver liberdade face a este conflito (entre emoção e razão)". ${ }^{10}$ Assim, a liberdade de pensar e de agir oportuniza o paciente a optar pelo que se entende ser o mais ideal para si. Quando não se tem liberdade para a escolha, o sujeito tende a perder sua possibilidade de autonomia. Por isso, entende-se que fatores externos podem deturpar a escolha pessoas, pois "es obvio que una elección causada,

\footnotetext{
${ }^{6}$ SANLLEHÍ, Josep, A vueltas con el principio de autonomía. In: CASADO, María. Estudios de Bioética y Derecho. Valencia: Tirant Lo Branch, 2000. p. 101.

7 DINIZ, Maria Helena. 0 estado atual do biodireito. 2. ed. São Paulo: Saraiva, 2002. p. 14.

${ }^{8}$ BELTRÃO, Silvio Romero. Autonomia da vontade do paciente e capacidade para consentir: uma reflexão sobre a coação irresistível. Revista de Direito Sanitário, [s.l.], v. 17, n. 2, p.98-116, 25 out. 2016. p. 105.

${ }^{9}$ Kant enfoca num sentido racional para a decisão autônoma, à qual a "vontade é aquela sua propriedade graças à qual ela é para si mesma a sua lei (independentemente da natureza dos objectos do querer). 0 princípio da autonomia é portanto: não escolher senão de modo a que as máximas da escolha estejam incluídas simultaneamente, no querer mesmo, como lei universal. Fundamentação da metafísica dos costumes. Lisboa: 70 Edições, 2007. p. 85.

${ }^{10}$ COHEN, Claudio; MARCOLINO, José Álvaro Marques. Relação Médico-Paciente. In: SEGRE, Marco; COHEN, Claudio. Bioética. 2. Ed. São Paulo: Editora da Universidade de São Paulo, 1999, p. 53.
} 
inducida o influída exclusivamente y de forma deliberada por otra persona no puede ser autónoma ni independiente". ${ }^{11}$

A liberdade tange tanto o agir, como também o pensar. Não pode haver autonomia na decisão sem livre pensamento. Uma vez capaz e consciente, o indivíduo deve ter plena possibilidade de uma ação autônoma, que se constitui da decisão voluntária do agente, da concepção, da livre deliberação, juntamente com suas crenças e preferências, formando assim, as razões para ação ${ }^{12}$. Nessa senda, a liberdade na autonomia constrói as características particulares do ser. De forma precisa, Beltrão preleciona que

[...] garantir a liberdade da pessoa significa permitir que esta mesma pessoa possa desenvolver sua personalidade de modo que sua atuação seja livre e autônoma. A pessoa é um ser em construção que não se realiza de forma prédeterminada ou herdada, mas que, na realidade, se molda pela própria ideia de autonomia e liberdade. ${ }^{13}$

Porém, destaca-se que essa liberdade não é um direito absoluto. Não se pode encarar o princípio da autonomia como um personalismo demasiado ignorando os outros sujeitos ao redor. As escolhas devem ter um mínimo ético que não viole outros princípios bioéticos, como o respeito à dignidade humana ou à objeção do profissional de saúde. ${ }^{14}$

Além da base principiológica, a autonomia da vontade encontra base legal, o que norteia sua efetivação no plano jurídico-político. No contexto do direito internacional, a Declaração de Direitos Humanos de 1948 preceitua em seu artigo XII que "ninguém será sujeito à interferência na sua vida privada, na sua família, no seu lar ou na sua correspondência, nem a ataque à sua honra e reputação [...]". Na Constituição da República Federativa do Brasil de 1988, observa-se no inciso II do artigo $5^{\circ}$, a desobrigação das pessoas fazerem ou deixarem de fazer algo sem a vontade $^{15}$. No que tange esse dispositivo constitucional, vale ressaltar que a liberdade fundamenta a vontade individual, sendo necessário a observação das obrigações impostas por lei.

\footnotetext{
11 SANLLEHÍ, Josep, A vueltas con el principio de autonomía. In: CASADO, María. Estudios de Bioética y Derecho. Valencia: Tirant Lo Branch, 2000. p. 104.

12 SANLLEHÍ, Josep, A vueltas con el principio de autonomía. In: CASADO, María. Estudios de Bioética y Derecho. Valencia: Tirant Lo Branch, 2000. p. 102.

${ }^{13}$ BELTRÃO, Silvio Romero. Autonomia da vontade do paciente e capacidade para consentir: uma reflexão sobre a coação irresistível. Revista de Direito Sanitário, [s.l.], v. 17, n. 2, p.98-116, 25 out. 2016. p. 109.

${ }^{14}$ MUÑOZ, Daniel Romero; FORTES, Paulo Antonio Carvalho. O Princípio da Autonomia e o Consentimento Livre e Esclarecido. In: COSTA, Sérgio Ibiapina Ferreira; GARRAFA, Volnei; OSELKA, Gabriel. Iniciação à Bioética. [s.l]: Conselho Federal de Medicina, 1998. p. 60-61.

${ }^{15} \mathrm{Art.} 5^{\circ}$, II: ninguém será obrigado a fazer ou deixar de fazer alguma coisa senão em virtude de lei.
} 
Já no Código Civil Brasileiro de 2002, o artigo 15 dispõe sobre a impossibilidade da submissão do indivíduo a algum tratamento médico ou intervenção cirúrgica sem real vontade; e como mandamento ético, o Código de Ética Médica, no artigo 24, expõe que é vedado ao profissional "deixar de garantir ao paciente o exercício do direito de decidir livremente sobre sua pessoa ou seu bem-estar, bem como exercer sua autoridade para limitá-lo".

Com esse curso rápido pelo princípio da autonomia, verifica-se a imprescindível necessidade de colocá-lo na ótica da análise de outros assuntos presentes na sociedade. A seguir, como ponto crucial para o trabalho, tem-se as implicações terapêuticas e legais sobre a Cannabis sativa.

\section{CANNABIS: ACEPÇÕES LEGAIS E TERAPÊUTICAS}

Antes de adentrar no objeto de estudos específicos, alguns apontamentos são necessários sobre a Cannabis. ${ }^{16}$ A planta Cannabis sativa L., como é conhecida cientificamente a maconha, está presente nas civilizações e em diferentes costumes dos povos. Originária das regiões tropicais asiáticas, sempre fora utilizada tanto para extração têxtil, em rituais religiosos, assim como para uso medicamentoso. ${ }^{17}$ Com a disseminação de informações e o contato dos povos, a

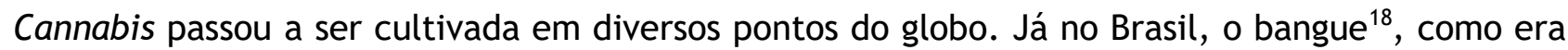
denominada a maconha, foi introduzido pelos escravos africanos no período colonial. Inicialmente, a maconha não teve seu uso recreativo restringido, principalmente por ser de uso mais comum da classe hipossuficiente. ${ }^{19}$

A partir dessas premissas, a discussão do presente trabalho debruça-se na investigação da inserção da Cannabis no ordenamento jurídico brasileiro e num entendimento mais apurado sobre suas qualidades medicamentosas e malefícios para o ser humano.

\subsection{Restrições e tipificação penal do consumo}

Com o advento da Conferência Internacional do Ópio em 1924, o Brasil iniciou sua política de controle da Cannabis $^{20}$. Já na década de 1930, surgem as primeiras intervenções policiais e o

\footnotetext{
${ }_{16}$ Para este trabalho se adotará essa grafia, sendo aqui considerada a variedade genérica da planta.

17 RIBEIRO, José António Curral. A Cannabis e suas aplicações terapêuticas. Dissertação (Mestrado) Curso de Ciências Farmacêuticas, Faculdade de Ciências da Saúde, Universidade Fernando Pessoa, Porto, 2014. p. 1-2.

18 Outras denominações para maconha são cânhamo da Índia ou marijuana.

${ }^{19}$ CARLINI, Elisaldo Araújo. A história da maconha no Brasil. Jornal Brasileiro de Psiquiatria, [s.l.], v. 55, n. 4, 2006. p. 315

${ }^{20}$ Mais especificadamente com o decreto número 4.294 de 1921.
} 
uso recreativo passa a ser considerado ilegal. O país seguiu uma tradição norte-americana de guerra às drogas ${ }^{21}$, com o intuito de exterminação dos diversos tipos de entorpecentes e higienização social.

A partir do ano de 2006 entrou em vigor a lei $n^{\circ}$ 11.343, também conhecida como Lei das Drogas. Esta, por sua vez, estabeleceu o Sistema de Políticas Públicas sobre Drogas dispondo sobre a proibição do uso das substâncias consideradas entorpecentes pela Agência Nacional de Vigilância Sanitária, a Anvisa. Um dos pontos a se colocar em questão foi indistinção entre usuário e traficante. ${ }^{22}$ A lei instituiu um tipo penal para o cultivo e o uso pessoal. Por isso, a partir da leitura do $\S 1^{\circ}$ do artigo 28 da referida lei percebe-se que "o plantio para consumo recebeu o mesmo tratamento jurídico-penal que o porte para consumo (art. 28), sendo previstas sanções alternativas à privação de liberdade". ${ }^{23}$

Ainda nessa esteira, encontra-se a tipificação no âmbito médico e farmacêutico do uso da Cannabis. Existe uma intensa modificação na legislação e nas regras para o uso medicamentoso da maconha no país atualmente. Com a resolução $n^{\circ}$ 2.113/14, o Conselho Federal de Medicina autorizou a prescrição médica para uso de medicamentos à base de Canabidiol $^{24}$, que mais à frente será destrinchado. Já em março de 2016, a Anvisa testificou a prescrição de medicamentos derivados da Cannabis sativa, como o próprio Canabidiol e o THC em quantidades controladas $^{25}$. Entretanto, uma resolução chave reacendeu o debate sobre o uso legal da planta Cannabis no cenário médico nacional. A resolução número 156/2017 da Anvisa tipificou a Cannabis sativa $L$. como planta medicinal. Com isso, amplia-se em grande escala as possibilidades sobre o uso das propriedades orgânicas da planta aqui estudada.

O Senado Federal disponibilizou no final de 2014 uma enquete virtual para obter a opinião pública sobre o uso medicinal da maconha. Dos resultados, suscitaram audiências

\footnotetext{
${ }^{21}$ Ou também War on Drugs, é uma expressão norte-americana que faz menção a um projeto de ofensiva ao combate ao tráfico popularizada pelo presidente Richard Nixon.

${ }^{22}$ Cf. GOMES, Luiz Flávio; SOUZA, Áurea Maria Ferraz. Tráfico ou usuário de droga: depende do caso concreto. 2010.

${ }^{23}$ SILVA, Felipe Figueiredo Gonçalves da. Não compre, plante?: Tipificação penal do cultivo de Cannabis pelo Tribunal de Justiça de São Paulo. Boletim: Publicação do Instituto Brasileiro de Ciências Criminais, [s.l], n. 286, p.20-22, set. 2016. p. 20.

${ }^{24}$ Destaca-se que a mesma resolução no artigo $4^{\circ}$ ressalta ser antiética a prescrição da Cannabis sativa in natura.

${ }^{25}$ BRASIL. Agencia Nacional de Vigilância Sanitária. Resolução da Diretoria Colegiada - RDC $N^{\circ} 66$, de 18 de Março de 2016. Brasília, 2016.
} 
públicas e debates a respeito do tema. Já a Anvisa, suscita a implementação de regras para plantio com objetivos de pesquisa. ${ }^{26}$

O tema já ganha repercussão nos tribunais chegando às instâncias superiores. Como será exposto à frente, um dos pontos que se discute no presente trabalho é a necessidade da ida ao judiciário para obter deferimento para uso medicinal da maconha. No STF, o Recurso Extraordinário 635.659 abriu o debate sobre a posse para uso pessoal da maconha. Por ser uma matéria de repercussão geral, tem se ouvido várias vertentes sobre o tema para que o debate seja completo. ${ }^{27}$

\subsection{Propriedades terapêuticas}

A Cannabis tem sido utilizada como base para medicamentos durante um longo curso da história. Encontra-se registros de uso da planta como insumo medicinal na China antiga, utilizada para problemas diversos. ${ }^{28}$ Tanto no seu uso in natura, como a manipulação para utilização dos derivados, a maconha esteve presente como subsídio em variados tratamentos. Em terras brasileiras, até "na década de 1930, a maconha continuou a ser citada nos compêndios médicos e catálogos de produtos farmacêuticos". ${ }^{29}$ Claramente, o uso tradicional começou a ser levado para o campo da ciência, no intuito de se comprovar cientificamente suas propriedades positivas no combate de patologias.

Hoje, sabe-se que na estrutura química da Cannabis sativa encontram-se mais de sessenta canabinoides ${ }^{30}$, psicoativos ou não, sendo que os mais comuns são o THC ( $\Delta^{9}$-tetrahidrocanabinol) e o Canabidiol (CBD). A primeira é a substancia com maior potencial psicoativo

${ }^{26}$ CANCIAN, Natália. Anvisa vai criar regras para cultivo de maconha medicinal. 2017. Disponível em: <http:// www1.folha.uol.com.br/equilibrioesaude/2017/07/1903558-anvisa-vai-criar-regras-para-cultivode-maconha-medicinal.shtml>. Acesso em: 21 ago. 2017.

${ }^{27}$ SILVA, José Edivaldo da; SILVA, Samuel Pereira da. Descriminalização ou legalização do uso Da maconha? E os projetos de lei sobre a Maconha descriminalizar ou legalizar? Cadernos de Graduação, [s.l], v. 3, n. 1, jul. 2017. p. 27-28.

${ }^{28}$ RIBEIRO, José António Curral. A Cannabis e suas aplicações terapêuticas. Dissertação (Mestrado) Curso de Ciências Farmacêuticas, Faculdade de Ciências da Saúde, Universidade Fernando Pessoa, Porto, 2014. p. 1.

${ }^{29}$ CARLINI, Elisaldo Araújo. A história da maconha no Brasil. Jornal Brasileiro de Psiquiatria, [s.l.], v. 55, n. 4, 2006. p. 316.

30 "O termo canabinóides (sic) foi atribuído ao grupo de compostos com 21 átomos de carbono presentes na Cannabis sativa, além dos respectivos ácidos carboxílicos, análogos e possíveis produtos de transformação." HONÓRIO, Káthia Maria; ARROIO, Agnaldo; SILVA, Albérico Borges Ferreira da. Aspectos terapêuticos de compostos da planta Cannabis sativa. Química Nova, [s.l.], v. 29, n. 2, p.318-325, abr. 2006. p. 319. 
na Cannabis. ${ }^{31}$ Esse composto apresenta fortes potencialidades e por isso é muito pesquisado, porém, analisado com ressalva, uma vez que é causador de dependência. Já a segunda substância, o cabinoide, não possui propriedade psicoativa, tornando-se alvo de inúmeras investigações e remédios já produzidos, uma vez que atua como anti-convulsivo e antiinflamatório.

Nesta senda, pode-se destacar algumas possibilidades de utilização dos canabinoides no tratamento de doenças. Uma das características marcantes da Cannabis sob o organismo humano são os efeitos no sistema nervoso. Com isso, o efeito de analgesia é uma das possibilidades para tratamento de dor, principalmente em situações que os remédios convencionais não proporcionam devida qualidade de vida; a utilização da maconha pode reduzir os sintomas e o tratamento quimioterápico em pacientes oncológicos ${ }^{32}$; uma forma muito conhecida e que mais incita a busca pela legalização é a esclerose múltipla e as síndromes epiléticas. 0 potencial anticonvulsivo e a atuação neurológica auxiliam na diminuição dos sintomas dessas enfermidades.

Não se pode deixar de ressaltar a produção de medicamentos que já é desenvolvida, como colocam Honório, Arroio e Silva:

dois exemplos de fármacos desenvolvidos com base em compostos canabinóides são o Marinol ${ }^{\circledR}$ (Dronabinol, (-) - $\mathrm{D}^{9}-\mathrm{THC}$ ), desenvolvido pelo laboratório Roxane (Columbus - EUA) e o Cesamet $^{\circledR}$ (Nabilone), desenvolvido pelo laboratório Eli Lilly (Indianápolis - EUA) e agora liberado para uso terapêutico no Reino Unido [...]. Estes medicamentos são comercializados para controle de náuseas produzidas durante tratamentos de quimioterapia e como estimulantes do apetite, durante processos de anorexia desenvolvidos em pacientes com síndrome da imunodeficiência adquirida (AIDS). ${ }^{33}$

Ressalta-se que todas essas doenças devem ser tratadas, diagnosticadas e medicadas corretamente por meio de orientação profissional. O uso indiscriminado da Cannabis não é benéfico e pode acarretar complicações, principalmente quando administrado de forma incorreta. Além disso, possíveis efeitos colaterais seguem junto às possibilidades terapêuticas

\footnotetext{
31 A concentração de $\Delta^{9}$-THC varia amplamente entre plantas de origens diferentes. A Cannabis sativa silvestre apresenta concentração de $\Delta^{9}$-THC na faixa de 0,5\% a 5\%29. Essas concentrações dependem das características genéticas do cultivar utilizado e do tipo de cultivo adotado. BRASIL. Senado Federal. Relatório Legislativo. Relator: Senador Cristovam Buarque. Sugestão № 8. Brasília, 2014.p. 30.

${ }^{32}$ MORAES, Ana Luísa. Substâncias da maconha ajudariam na luta contra o câncer. 2017. Disponível em: $<$ http://saude.abril.com.br/medicina/substancias-da-maconha-ajudariam-na-luta-contra-o-cancer/>. Acesso em: 20 jul. 2017.

33 HONÓRIO, Káthia Maria; ARROIO, Agnaldo; SILVA, Albérico Borges Ferreira da. Aspectos terapêuticos de compostos da planta Cannabis sativa. Química Nova, [s.l.], v. 29, n. 2, abr. 2006. p. 320.
} 
benéficas como "alterações na cognição e memória, euforia, depressão, efeito sedativo e outros". ${ }^{34}$

Um contraponto importante é sobre os efeitos negativos do uso da Cannabis. A restrição existente se justifica pelo aspecto entorpecente presente na planta. 0 seu uso in natura e sob administração na forma de fumo acarretam malefícios à saúde dos usuários, como quadros clínicos de psicose. Por esses motivos, Quevedo registra que, sobre o uso medicinal da maconha:

la OMS ha prevenido que la fitoterapia carece de datos producidos por investigaciones, mecanismos de control apropiados, educación y capacitación, experiencia de trabajo dentro de las agencias nacionales de salud y de control, comunicación de la información, monitoreo seguro, y de métodos para evaluar la eficacia y seguridad. ${ }^{35}$

Dessa forma, levando em consideração essas premissas, o que se pretende em toda a presente discussão é um levantamento dos benefícios já comprovados por meio de testes laboratoriais e clínicos. Tais benefícios são o cerne da discussão e por isso ganham destaque na pesquisa.

Consignadas as premissas até aqui levantadas, busca-se em seguida a análise dos aspectos que orbitam o uso medicinal da maconha sob a ótica do princípio da autonomia da vontade.

\section{AUTONOMIA DA VONTADE VS RESTRIÇÃO DO USO MEDICINAL DA MACONHA}

Após o perpasse pela investigação do conteúdo teórico e normativo do princípio da autonomia da vontade e dos aspectos legais e medicinais que tangenciam a Cannabis, procede-se agora com a contraposição do princípio referido em face da restrição do uso terapêutico da maconha.

Ao se discutir sobre o uso da maconha para determinado fim, sejam nas instâncias jurídicas ou sociais, a questão quase sempre se resvala no impasse sobre a descriminalização das drogas. Porém, o debate sobre essa problemática é denso e não pertence de forma correlata ao presente estudo, contudo é um ponto que tangencia a discussão e deve ser contraposto brevemente.

\footnotetext{
34 Ibid., p. 320.

35 QUEVEDO, Lenin de Ramon. Cannabis y medicina tradicional: libertad, sociabilidad y subsidiariedad de este tipo de fitoterapia. Vida y Ética, [s.l], v. 1, ano 16, jun. 2015. p. 67.
} 
Diante disso, sabe-se que o cultivo para uso medicinal e o cultivo para uso recreativo são diferentes, contudo, na prática exigem um mesmo nível de fiscalização. Resta ausente uma efetivação das decisões legislativas com o intuito de definir essa temática e de diferenciar as questões.

O poder legislativo é destoante perante a matéria, pois perpassa na discussão sobre a legalização das drogas, sobretudo da maconha, tornando-se um gargalo entre os parlamentares. Isto se dá pelo fato de que grupos pró-legalização da Cannabis para uso recreativo e pessoal embarcam na campanha em defesa do uso medicinal da planta. Mesmo lícita a junção de forças para se atingir determinados objetivos, tal mescla de grupos de interesses acaba dificultando a fluidez do debate para legalização do uso medicinal da Cannabis. 0 cenário legislativo atual, o qual se mostra um tanto conservador ao debater questões com grau elevado de complexidade social, impõe a necessidade da disjunção dos fins de uso medicinal e uso recreativo da maconha na militância junto ao parlamento brasileiro. ${ }^{36}$

Ainda nesta senda, mesmo com diversos avanços na pesquisa clínica atestando a possibilidade de tratamento de doenças por meio de extratos da maconha, a sociedade ainda tem um estigma sobre a utilização da Cannabis. A maconha tem em si o fato de ser uma droga, ou seja, "carrega consigo uma série de conotações. Pode se referir a medicamentos, a uma interjeição a algo que não corresponde à expectativa ou, por fim, pode relacionar-se com substâncias psicoativas [...]". ${ }^{37}$ Parece ser algo meramente do campo moral da sociedade brasileira, mas, uma vez continuamente estereotipada, a maconha sofre resistência para se inserir no cotidiano das pessoas até mesmo como medicamento. Por isso, Carmen Pávon coloca, sobre a Cannabis, que

la polémica respecto a su uso médico se produce porque por la mayoría de las legislaciones está considerado como una droga de abuso. Lo cual hace que se cree una idea negativa, en muchos casos preconcebida por la falta de información de la población, y se presuponga su peligrosidad para la salud, negando los posibles beneficios que pueda tener. Por tanto, en una posible legalización, se antepondrían las ideas negativas y los estigmas, a un posible efecto beneficioso para algunas enfermedades. ${ }^{38}$

\footnotetext{
${ }^{36}$ Cf. CREMESP. Desinformação e má-fé permeiam o debate sobre liberação do canabidiol no Brasil. Jornal do Cremesp. [s.l], jun. 2014. p. 16.

37 LIMA FILHO, Francisco de Assis. Todo vagabundo é maconheiro, mas nem todo maconheiro é vagabundo": Um estudo com consumidores estáveis de maconha. Dissertação (Mestrado) - Curso de Psicologia, Universidade Federal do Espírito Santo, Vitória, 2010. p.19.

38 PAVÓN, Carmen Osorio. Uso terapéutico del cannabis. 2016. 25 f. TCC (Graduação) - Curso de Enfermagem, Universidad de Cantabria, Cantabria, 2016. p. 15.
} 
Neste sentido, ao se retomar os aspectos intrínsecos ao princípio da autonomia, verificase o quão difícil é para o paciente tomar uma decisão, já que não há total liberdade e, consequentemente, uma impossibilidade de opção. Como já foi mostrado “[...] a liberdade e a opção para uma determinada finalidade estruturam um campo de relação que é o alicerce da autonomia". ${ }^{39}$ Mais do que isso:

para que exista uma ação autônoma (liberdade de decidir, de optar) é também necessária a existência de alternativas de ação ou que seja possível que o agente as crie, pois se existe apenas um único caminho a ser seguido, uma única forma de algo ser realizado, não há propriamente o exercício da autonomia. ${ }^{40}$

A partir dessas considerações, é possível denotar que uma das barreiras para uma decisão autônoma do paciente frente ao seu tratamento médico, está no fato de a restrição legal do uso da maconha causar um desconforto intrínseco ao enfermo. A construção social, advinda da latente guerra às drogas, acaba por desqualificar a pesquisa e os aspectos benéficos que a Maconha dispõe ao paciente. Como dito acima a falta de informação concebe conceitos equivocados no seio de uma sociedade, tendo em vista a consequente associação da Maconha como algo unicamente maléfico e ilegal.

O impedimento, no tocante ao uso médico da Cannabis, inibi o indivíduo e acaba coagindo-o internamente, não permitindo assim total liberdade de escolha e de pensamento sobre a questão. Em passagem precisa, Beltrão mostra que "a autonomia é um espaço de liberdade que é reconhecido à pessoa para desenvolver sua vida de acordo com seus interesses e valores". ${ }^{41}$ Portanto, a percepção que a legislação vigente traz sobre a maconha proporciona já no paciente uma dificuldade de uma formulação de uma vontade insípida.

À luz da ideia estruturante do princípio da autonomia da vontade é observável um cenário embaraçoso: Existe uma série de doenças de difícil tratamento; há uma base de pesquisa indicando as propriedades terapêuticas da maconha sob tais doenças; e se mantém um debate lento e estigmatizado sobre uma liberação mais genérica e responsiva do uso da Cannabis sativa para uso medicinal.

${ }^{39}$ COHEN, Claudio; MARCOLINO, José Álvaro Marques. Relação Médico-Paciênte. In: SEGRE, Marco; COHEN, Claudio. Bioética. 2. ed. São Paulo: Editora da Universidade de São Paulo, 1999. p. 53.

${ }^{40}$ MUÑOZ, Daniel Romero; FORTES, Paulo Antonio Carvalho. O Princípio da Autonomia e o Consentimento Livre e Esclarecido. In: COSTA, Sérgio Ibiapina Ferreira; GARRAFA, Volnei; OSELKA, Gabriel. Iniciação à Bioética. [s.l]: Conselho Federal de Medicina, 1998. p. 57.

${ }^{41}$ BELTRÃO, Silvio Romero. Autonomia da vontade do paciente e capacidade para consentir: uma reflexão sobre a coação irresistível. Revista de Direito Sanitário, [s.l.], v. 17, n. 2, p.98-116, 25 out. 2016. p. 108. 
Outrossim, o paciente, devidamente capaz e consciente de seu estado clínico e dos métodos de tratamento, tem no uso medicinal da maconha uma oportunidade de ação e de optar por um método, o qual, muitas vezes, só é eficaz com o extrato da maconha. Porém, sua liberdade de agir e de optar se resvala na restrição que interfere de forma negativa no princípio da autonomia do indivíduo.

Como foi salientado, atualmente existem formas de adquirir a planta ou o extrato, assim como cultivar a maconha no Brasil. No entanto, ainda com esse avanço, o princípio da autonomia é restringido. Primeiramente, a importação do produto exige adentrar numa gama de procedimentos burocráticos, desde a solicitação até o envio da encomenda. Já o cultivo legal só é possível por medidas judiciais, as quais, por ser um tema polêmico, acaba sendo de difícil resolução. A segunda questão envolve as populações hipossuficientes. Tanto a importação do produto como a entrada no judiciário demandam um extenso acesso à informação e um considerável poder econômico.

Desse modo, enfermos de classes sociais com restrições monetárias não dispõem dos mesmos recursos de outros pacientes para ter acesso aos medicamentos e tratamentos à base da Cannabis. Esse cenário resulta numa violação aos direitos fundamentais dos cidadãos, já que, para essas pessoas, é inviável o atual contexto do uso terapêutico da maconha.

Mais do que isso, o não acesso a esse recurso fármaco leva as pessoas às atividades clandestinas, como contrabando, cultivo sem autorização ou até mesmo compra por meio do tráfico drogas. No entendimento de Figueiredo e Otero:

quando essa modalidade de terapia deixa de ser contemplada pela regulamentação da Anvisa, pacientes são expostos ao risco de sofrerem consequências penais por autotutelarem direitos fundamentais, cultivando e produzindo, para si ou para outrem, remédios à base de extratos da planta para o cuidado de suas doenças. ${ }^{42}$

Surge, portanto, uma dualidade situacional: o próprio paciente efetiva o direito à dignidade humana, do autogoverno, do direito à saúde, que o Estado deveria garantir, enquanto os órgãos públicos restringem a efetivação desses direitos e subtraem de si a prerrogativa da promoção de tais direitos. Com esse cenário, o cidadão é obstruído de buscar aquilo que é melhor para si, de acordo com seu entendimento informado. De forma acertada coloca o Ministro Barroso:

\footnotetext{
42 FIGUEIREDO, Emílio Nabas; OTERO, Lorena. Entre a criminalidade e a constitucionalidade: o cultivo e produção de cannabis para fins terapêuticos. Boletim: Publicação do Instituto Brasileiro de Ciências Criminais, [s.l], n. 286, set. 2016. p. 22.
} 
A liberdade é um valor essencial nas sociedades democráticas. Não sendo, todavia, absoluta, ela pode ser restringida pela lei. Porém, a liberdade possui um núcleo essencial e intangível, que é a autonomia individual. Emanação da dignidade humana, a autonomia assegura ao indivíduo a sua autodeterminação, o direito de fazer as suas escolhas existenciais de acordo com as suas próprias concepções do bem e do bom. Cada um é feliz à sua maneira. A autonomia é a parte da liberdade que não pode ser suprimida pelo Estado ou pela sociedade. ${ }^{43}$

O voto supracitado do Ministro do Supremo Tribunal Federal elenca diversos direitos fundamentais inerentes à questão aqui tratada. A autonomia da vontade e mais especificamente a autonomia da vontade do paciente, é fundamentada, como já exposto, na liberdade de escolha, na autodeterminação. E mais, como bem coloca Roberto Barroso, a autonomia advém do princípio da dignidade da pessoa humana, o qual foi positivado na Constituição Federal de 1988, no inciso III do art. $1^{\circ}$, e subscrito na Declaração de Direitos Humanos de 1948.

De forma breve, o princípio da dignidade humana norteia os mais variados aspectos da vida, sendo que o que se pretende é uma vida digna, com integridade moral e psíquica independente da condição que esteja o indivíduo. ${ }^{44}$ Sarlet preleciona que o referido princípio fundamental é um referencial para todos os outros preceitos fundamentais, seja na interpretação, seja na aplicabilidade. ${ }^{45} \mathrm{Em}$ um de seus escritos, Luís Roberto Barroso entende a autonomia como um dos elementos essências à dignidade humana. Ele ensina que:

\begin{abstract}
a autonomia é o elemento ético da dignidade, ligado à razão e ao exercício da vontade na conformidade de determinadas normas. A dignidade como autonomia envolve, em primeiro lugar, a capacidade de autodeterminação, o direito do indivíduo de decidir os rumos da própria vida e de desenvolver livremente sua personalidade. Significa o poder de fazer valorações morais e escolhas existenciais sem imposições externas indevidas. ${ }^{46}$
\end{abstract}

$\mathrm{Na}$ brilhante exposição, pode-se notar que a discussão toca os princípios fundamentais dos indivíduos. Ao tomar como base o ensinamento de Barroso, depreende-se que a vida digna está inteiramente ligada a possibilidade e a capacidade de o sujeito agir e escolher livremente.

\footnotetext{
${ }^{43}$ BRASIL. Supremo Tribunal Federal. Recurso Extraordinário $n^{\circ}$ 635.659. Julgamento Sobre Porte de Drogas Para Consumo Próprio: Voto oral Ministro Luiz Roberto Barroso. Brasília, 2017. p. 8

44 BRASIL. Supremo Tribunal Federal. Recurso Extraordinário $n^{\circ} 635.659$. Julgamento Sobre Porte de Drogas Para Consumo Próprio: Voto oral Ministro Luiz Roberto Barroso. Brasília, 2017. p. 273.

45 SARLET, Ingo Wolfgang. A eficácia dos Direitos Fundamentais. Porto Alegre: Livraria do Advogado, 1998. p. 98.

46 BARROSO, Luís Roberto. A Dignidade da Pessoa Humana no Direito Constitucional Contemporâneo: Natureza Jurídica, Conteúdos Mínimos e Critérios de Aplicação. Versão provisória para debate público. Mimeografado. [s.l], 2010. p. 24.
} 
Trazendo as questões anteriormente levantadas ao que se discute no presente trabalho, observa-se que existe um paradigma entre a restrição do uso medicinal da maconha e os princípios fundamentais levantados. Isso, pois, como suscitado em tópicos anteriores, existe uma plausível possiblidade de os pacientes com determinadas patologias utilizarem o que se tem atualmente de pesquisa médica sobre o uso da maconha para fins terapêuticos.

A vida digna mostra-se afetada pela impossibilidade ou pela dificuldade enfrentada pelos pacientes que necessitam do acesso aos tratamentos à base da Cannabis. Desse modo, o impedimento legal do uso medicinal da maconha toca e limita o direito de escolha do tratamento e permeia a restrição de uma plena eficácia da dignidade humana.

Mesmo a presente discussão tratando especificadamente do princípio da autonomia da vontade, tal fundamento abre precedente para refletir em outros aspectos que a Bioética e o Biodireito trazem para esse tema.

A restrição da Cannabis interfere decisivamente no bem-estar do paciente. Assim, é possível invocar o princípio da benevolência que a partir do juramento de Hipócrates dá as premissas de fazer o bem e favorecer a qualidade de vida. ${ }^{47}$ Tal princípio coloca em cheque a própria possibilidade do profissional de saúde poder proporcionar ao enfermo o tratamento que permita a melhora de sua condição clínica, levando a questão de que a restrição do uso medicinal da Cannabis interfere também na atuação médica.

O princípio da benevolência alinha-se ao princípio bioético da justiça que visa "garantir uma distribuição justa, equitativa e universal dos bens e serviços (dos benefícios) de saúde". ${ }^{48}$ É evidente que a obtenção dos fármacos advindos da Cannabis exige um grande esforço judicial e financeiro, impossibilitando que esse benefício chegue a todos equitativamente.

Wolfgang Sarlet, escrevendo sobre a vinculação do poder público aos direitos fundamentais expõe que "se aponta a necessidade de todos os poderes públicos respeitarem o âmbito de proteção dos direitos fundamentais, renunciando, em regra, a ingerências, a não ser que presente justificativa os autorize". ${ }^{49} \mathrm{Na}$ linha do jurista brasileiro, o Estado deve efetivar de forma imediata os direitos fundamentais dispostas no âmbito constitucionais. Uma vez que órgãos estatais não caminham frente às inúmeras manifestações que a academia médica e os próprios pacientes têm pautado sobre a possibilidade de tratamentos advindos da maconha, os

\footnotetext{
${ }^{47}$ FABRIZ, Daury Cesar. Bioética e direitos fundamentais. Belo Horizonte: Mandamentos, 2003. p. 107.

48 Ibid., p. 111.

${ }^{49}$ SARLET, Ingo Wolfgang. A eficácia dos Direitos Fundamentais. Porto Alegre: Livraria do Advogado, 1998. p. 98. p. 323.
} 
preceitos fundamentais da dignidade da pessoa humana, sobretudo o elemento cerne da autonomia da vontade, comprometem-se.

Antes do avanço do trabalho, convém ressaltar mais uma vez uma baliza imprescindível do princípio da autonomia da vontade, o qual deve ser livre e esclarecido. Dessa forma, qualquer circunstância que obstrua o conteúdo da vontade, na sua real expressão, descontrói a ideia central do referido princípio. Isso, pois, “para ser considerada juridicamente valida, a vontade deve ser autônoma e livre de influência que a contamine" ${ }^{50}$, ou seja, deve-se afastar qualquer influência externa ou interna que embarace a tomada de decisão.

Em um contexto de enfermidade com alto grau de complexidade, de elevado risco à vida e de indícios de irreversibilidade, a autonomia da vontade do paciente pode se comprometer. Por isso, destaca-se que antes mesmo de se decidir sobre o tratamento, seja ele tradicional ou alternativo, como no caso dos métodos aludidos neste trabalho, é necessário que se verifique a capacidade do indivíduo decidir. Isso impõe o afastamento das influências internas como a dor física, as emoções afloradas, a depressão, etc., mas também, influências externas como o desejo dos familiares, a pressão médica, o ambiente hospitalar. ${ }^{51}$ Assim, ao se colocar essas questões de lado afasta a possibilidade de uma ação involuntária do paciente.

$\mathrm{Na}$ discussão supra, pode-se observar a complexidade que tangencia a questão levantada. De todo modo, emergir nesse debate se faz necessário na tentativa de solucionar os pontos ainda controvertidos na temática.

Em seguida, adentrar-se-á nos aspectos pragmáticos da temática para uma percepção breve e exemplificadora sobre a atualidade da problemática.

\section{O USO MEDICINAL DA CANNABIS NO CONTEXTO BRASILEIRO}

No Brasil, alguns pacientes utilizam os benefícios terapêuticos da Cannabis, mitigando, de certo modo, a restrição legal. Com uma legislação ainda insuficiente, as decisões judiciais nos casos concretos têm definido sobre o uso medicinal por meio de remédios e de extratos, o cultivo da planta e as pesquisas na área.

Os casos trazidos para análise foram divulgados pela indústria cinematográfica e pelos meios de informações nos últimos anos. Busca-se um perpasse empírico e sobre os indivíduos que buscam os tratamentos à base do Canabidiol no Brasil, com a finalidade de exemplificar o que já

\footnotetext{
${ }^{50}$ BELTRÃO, Silvio Romero. Autonomia da vontade do paciente e capacidade para consentir: uma reflexão sobre a coação irresistível. Revista de Direito Sanitário, [s.l.], v. 17, n. 2, p.98-116, 25 out. 2016. p. 107. 51 lbid., p. 104.
} 
foi aludido nos pontos anteriores. Como forma de resguardar a identidade das pessoas, utilizarse-á apenas a inicial do prenome e o sobrenome.

Primeiramente, o episódio com a menina A. Fischer foi emblemático e motivador de inúmeros debates no país sobre o uso medicinal da maconha. Este caso em especial ficou conhecido pelo documentário llegal (2014), dirigido por Tarso Araújo e Raphael Erichsen, mostrando a importância dos meios de comunicação e de como ele tem incidido sob o tema.

Assim como várias famílias, K. e N. Fischer, pais de A., obtiveram informações sobre determinado remédio que ajudaria no controle sintomático da encefalopatia epiléptica infantil precoce (tipo 2$)^{52}$, doença que acomete a filha do casal. Para tanto, usaram meios alternativos para a importação do medicamento dos Estados Unidos da América. Em um dos envios para o país, o produto ficou retido na alfândega impedindo que a criança pudesse ser medicada. A partir disso, a família de A. recorreu às vias judiciais para ter a autorização da importação do remédio, conseguindo no ano de 2014.

Neste caso, verifica-se como as regras administrativas põem em risco a saúde da criança e ignora o fato da escolha da paciente do único remédio que surte efeito para minimizar as convulsões. Ao observar as formas indevidas que a família utilizou para obter o medicamento, fica evidente que a restrição impede a opção do paciente em ter acesso àquilo que unicamente pode amenizar o sofrimento e dar um pouco mais de bem-estar.

Outro caso envolvendo uma menor é o de C. Carvalho. Ela teve sua história repercutida em cenário nacional ${ }^{53}$ e trouxe à tona a problemática do cultivo pessoal da Cannabis. Aos onze anos ela foi diagnosticada com a Síndrome de Dravet $^{54}$, patologia que

\footnotetext{
52 Variação rara e de difícil controle da Síndrome de Rett que "caracteriza-se por perda de interesse pelo meio, associada à regressão da habilidade de comunicação e pela presença de movimentos estereotipados, especialmente das mãos, que deixam de ser utilizadas com um propósito. Há ainda desaceleração da velocidade de crescimento craniano, alterações da frequência respiratória com períodos de hiperpneia intercalados por apneia, bruxismo, escoliose e, com frequência, epilepsia. Nas crianças que mantém a habilidade de caminhar, observa-se ataxia e apraxia da marcha". USP. Síndrome de Rett. [S.d]. Disponível em: <http://www.genoma.ib.usp.br/pt-br/servicos/consultas-etestes-geneticos/doencas-atendidas/sindrome-de-rett>. Acesso em: 24 jul. 2017.

53 Cf. CANCIAN, Natália. Justiça autoriza pais a plantar maconha em casa para tratar filhos. 2017. Disponível em: <http://www1.folha.uol.com.br/equilibrioesaude/2017/01/1850088-justica-autoriza-paisa-plantar-maconha-em-casa-para-tratar-filhos.shtml>. Acesso em: 26 jun. 2017.

54 "El síndrome de Dravet es una forma severa de epilepsia, de origen genético, que se inicia en la más temprana infancia, generalmente antes del primer año de edad, y se caracteriza por la presencia de diferentes tipos de crisis convulsivas, en ocasiones desencadenadas por diferentes estímulos como la fiebre [...]. El síndrome de Dravet se considera una enfermedad rara cuya incidencia es de 1/20.000 a $1 / 40.000$ nacidos vivos y cuya prevalencia es del $7 \%$ de las epilepsias en menores de 3 años. Afecta a varones y mujeres por igual y se da en todo el mundo." CASTILLO, M. ${ }^{a}$ Mercedes Mingarro et al. Síndrome de Dravet. Revista Clínica de Medicina de Familia, [s.l.], v. 7, n. 2, p.134-136, jun. 2014. p. 134.
} 
dificilmente os remédios disponíveis surtem efeitos para diminuição dos sintomas. Por esses motivos, seus pais, M. A. de Carvalho e F. de Carvalho, impetraram habeas corpus solicitando o cultivo da erva, conseguindo no final de 2016 uma decisão favorável.

O pedido foi feito, pois, como já mencionado, a Cannabis sativa ajuda a minimizar os sintomas epiléticos. Antes da produção na residência familiar, os pais de $C$. haviam recorrido a redes ilegais de importação e foram ao Chile conhecer o preparo do medicamento. Com essa autorização, a família Carvalho é uma das primeiras do país a conseguir cultivar uma variedade de Cannabis na própria casa.

Tanto neste, como no episódio de A. Fischer, os familiares adotaram inicialmente os meios ilícitos para obtenção do produto à base de canabidiol. Isso demonstra factualmente a autotutela da liberdade e do direito de escolha, mas também do próprio direito à saúde, já que o Estado impede tais garantias a esses pacientes.

Finalmente, é importante destacar as entidades que produzem os medicamentos à base de maconha e pesquisam sobre as propriedades terapêuticas da planta. A Justiça Federal da Paraíba permitiu liminarmente que a Associação Brasileira de Apoio Cannabis Esperança - Abrace - cultivasse e manipulasse a erva para fins medicinais. ${ }^{55}$ Tal decisão, de caráter pioneiro no Brasil, permite que os associados à organização possam comprar os produtos dentro de regras estabelecidas. A Juíza Dr. Wanessa Lima também estabeleceu uma série de diretrizes para que a associação siga.

Outro aspecto são as atividades dos centros de ensino. A Universidade de São Paulo Campus Ribeirão Preto idealizou o Centro de Pesquisas em Canabidioides da Faculdade de Medicina de Ribeirão Preto, que tem por objetivo o desenvolvimento de medicamentos e testes certificados em pacientes problemas neurológicos ${ }^{56}$. Já a Fundação Oswaldo Cruz e a Universidade Federal do Rio de Janeiro formaram parceria para também desenvolverem medicamentos à base da maconha. Além disso, iniciou-se o projeto Farmacannabis, no qual investiga a composição dos remédios industrializados importados e dos confeccionados artesanalmente ${ }^{57}$.

\footnotetext{
${ }^{55}$ Cf. REDAÇÃO. Associação ganha direito de fazer cultivo medicinal de maconha. 2017. Disponível em: $<$ http:// www.jornaldaparaiba.com.br/vida_urbana/noticia/183989_associacao-ganha-direito-de-fazercultivo-medicinal-de-maconha>. Acesso em: 26 jul. 2017.

${ }^{56}$ Cf. STELLA, Rita. USP terá primeiro centro de pesquisa em canabidiol do País. 2017. Disponível em: <http://jornal.usp.br/universidade/usp-tera-primeiro-centro-de-pesquisa-em-canabidiol-do-pais/>. Acesso em: 27 jul. 2017.

57 Cf. MATOS, Alexandre. Projetos na UFRJ e Fiocruz para desenvolver medicamento à base de maconha. 2017. Disponível em: <http://www.far.fiocruz.br/2017/01/projetos-na-ufrj-e-fiocruz-paradesenvolver-medicamento-a-base-de-maconha/>. Acesso em: 26 jul. 2017.
} 
Um ponto destacável é que não havendo linhas amplas de pesquisa, por conta da restrição também para esse fim, a produção de conhecimento sobre a matéria se limita. Essa situação não permite o desenvolvimento de remédios de fácil acesso para todos os cidadãos e, mais uma vez, não permite ao paciente de uma determinada doença escolher seu tratamento, pois a opção aqui discutida não é possível. Isso levanta também um debate sobre a saúde pública e o próprio direito constitucional de se promover os meios de saúde a todos.

\section{BREVE PANORAMA SOBRE O TRATAMENTO LEGAL DADO AO USO MEDICINAL DA MACONHA FORA DAS FRONTEIRAS NACIONAIS}

Após descrever acerca do atual cenário brasileiro, faz-se necessário um levantamento, mesmo que breve, do panorama sobre o tratamento legal dado ao suo medicinal da maconha fora das fronteiras nacionais. Para tanto, selecionou-se a Holanda, o Uruguai, a Argentina, Israel e os Estados Unidos da América. Tais países são objetos de análise, pois são exemplos de nações que introduziram em suas respectivas legislações no tocante da liberação da maconha em contextos diferentes. Com isso, busca-se nos tópicos a seguir, uma breve descrição sobre realidades internacionais e posteriormente um quadro de comparação entre esses diferentes ordenamentos.

\section{- Holanda}

A Holanda se destaca como um dos países pioneiros na descriminalização da maconha em seu território. A partir de 1976 o país adotou medidas liberais de não punição aos portadores com trinta gramas da planta. De forma paulatina, o governo tinha como objetivo a distinção dos usuários de drogas com maior teor entorpecente dos consumidores da maconha, retirando-os da marginalização. Primeiramente houve um aumento do consumo e após a instituição do Coffe Shop - local autorizado para venda e consumo da maconha - houve uma queda no número de usuários. ${ }^{58}$

Tais políticas demonstram que a Holanda encara as problemáticas relacionadas às drogas como uma questão de saúde pública e por isso fornecem assistência médica aos usuários no intuito de bem-estar de sua população. Frisa-se que o consumo da maconha é controlado e regulamentado, só podendo ser utilizada em locais adequados.

\footnotetext{
58 LUCENA, Willian Felipe. As políticas de legalização da maconha: Uma discussão baseada em evidências. 2012. 27 f. Monografia (Especialização) - Curso de Especialização em Dependência Química, Universidade Federal de São Paulo, São Paulo, 2012. p. 14.
} 


\section{- Uruguai}

Certamente a nação uruguaia se destacou na América-latina após liberar a Cannabis. A lei de maio de 2014 possibilita aos uruguaios o cultivo pessoal da planta, a participação de clubes de usuários e a compra limitada da maconha. A legislação, teve seu desfecho em junho de 2017, quando as farmácias iniciaram a comercialização da planta. Semanalmente, os cidadãos podem adquirir dez gramas da droga, após terem se inscrito no cadastro obrigatório de usuários.

No caso do Uruguai, a lei $n^{\circ} 19.172 / 14$ não se limita aos objetivos medicinais para a referida liberação. 0 objetivo do novo ordenamento tem por propósito "combater o tráfico de drogas e seus impactos diretos e indiretos sob a sociedade uruguaia". ${ }^{59}$ Com isso a restrição deixa de ser um impeditivo tanto para os usuários que necessitam da planta para uso médico, tanto para os que utilizam de forma recreativa. Contudo, frisa-se que toda a atividade é controlada pelo Estado, o qual proíbe qualquer difusão midiática da droga. Para controle administrativo, o governo formalizou o Instituto de Regulación e Control del Cannabis - IRCCA - que tem por objetivo a fiscalização do produto e sua comercialização, bem como o licenciamento do cultivo, dos usuários e dos clubes canábicos. ${ }^{60}$

\section{- Argentina}

Desde de 2009, o governo argentino iniciou um processo de despenalização às pequenas quantidades de maconha consumidas em lugares particulares. Visou-se com isso, um investimento maior no controle no tráfico e no subsídio médico aos usuários de drogas. ${ }^{61}$

No início de 2017 a Argentina legalizou a importação de medicamentos derivados da maconha. A decisão do senado argentino partiu das demandas de associações de pais de crianças com determinadas doenças, principalmente epilepsia. A partir disso, o país garante o acesso a medicamentos importados à base da Cannabis até que o Estado possa fornecer ou tenha condições de avançar no tocante ao uso terapêutico da maconha no território nacional. ${ }^{62} \mathrm{O}$ projeto abarca também o estudo sobre as possíveis propriedades terapêuticas

59 FERRARI, Dércio Fernando Moraes; NERES, Geraldo Magella. Políticas públicas no uruguai em tempos de mujica: o impacto da legalização do aborto e da maconha sobre a mídia digital brasileira. Tempo da Ciência, [s.l], v. 22, n. 43, jan/jul. 2015. p. 59.

60 lbid., p. 58-60.

61 ZANATTO, Rafael Morato. Maconha: Weltanschauung em trans - form - ação! Boletim Maconhabrás. [s.l], dez. 2015. p. 6.

62 BARREIRO, Ramiro. Argentina aprueba el uso medicinal de la marihuana. 2017. Disponível em: <https://elpais.com/internacional/2017/03/30/actualidad/1490830376_425239.html>. Acesso em: 17 ago. 2017. 
da maconha, regulamentando o estudo de medicamentos para minimização de doenças como epilepsia e Alzheimer.

- Israel

O Estado israelense é um exemplo de nação que manteve a proibição do uso recreativo da maconha, mas que já tem a planta como subsídio para tratamento de determinadas doenças. Desde a década de 1990, o país autoriza pacientes a utilizarem medicamentos à base de substancias presentes na Cannabis. Seu potencial global no estudo da maconha medicinal se exemplifica na descoberta do THC pelo médico e químico israelense Raphael Mechoulam, professor do instituto Wizemann. ${ }^{63}$

\section{- Estados Unidos da América}

Por conta de sua característica federalista, cada estado americano possui legislação própria em relação ao uso da maconha. No âmbito federal, a maconha permanece como uma droga ilícita. Porém, em agosto de 2016 o Drug Enforcement Administration, órgão destinado para a classificação das substâncias nos EUA, reclassificou a maconha como planta com potencial medicinal. ${ }^{64} \mathrm{~A}$ nível estadual, já são mais de vinte estados americanos com legislação a favor do uso medicinal da Cannabis. Os estados do Colorado e de Washington são exemplos de localidades em que a maconha foi liberada também para o consumo recreativo. 0 país é um dos grandes fornecedores de medicamentos para o mundo e desenvolve uma extensa linha de pesquisa sobre as finalidades terapêuticas da maconha. Essa questão levanta um ponto importante do quanto a Cannabis pode beneficiar os aspectos econômicos e financeiros. Um dos pontos levantados.

Uma das justificativas contrárias à liberação medicinal inferia que a autorização para o uso terapêutico da maconha levaria o aumento do consumo da droga. Nessa senda, a questão da violência relacionada aos usuários da maconha foi suscitada como possível ponto negativo após a liberação. Essas duas questões foram analisadas em várias localidades. Tanto o nível

${ }^{63}$ ROSA, Gabriel Pesca da. Cannanis medicinal: Entre os saberes das ciências sociais e biomedicina. 2016. 47 f. TCC (Graduação) - Curso de Ciências Sociais, Universidade Federal de Santa Catarina, Florianópolis, 2016. p. 15.

64 Ibid., p. 24. 
de consumo, como a criminalidade relacionada a usuários, ou diminuiu, ou manteve-se as taxas anteriores. ${ }^{65}$

Analisando os países supracitados, percebem-se características relevantes. A Holanda e seu pioneirismo deram uma forte abertura e um modelo a ser adaptado em outros países. No caso dos Países Baixos, a discussão foi mais ampla que a despenalização do uso medicinal da maconha e abarcou todas as questões sociais que envolvem o consumo da droga. Nessa mesma linha, o Uruguai tomou frente na América Latina nesse tocante. Um elemento importante foi a criação de um órgão governamental competente para o controle das atividades envolvendo a Cannabis. Isso, pois, a liberação, seja para uso recreativo, seja para uso medicinal, exige um controle dentro de um país.

A vizinha Argentina consagra o exemplo de uma forma paliativa para tratar o problema: Regulamentação e liberação de medicamentos enquanto o país não tem uma devida saída originária para essa questão. Isso permite que o princípio da autonomia não seja interferido ou que sua violação não seja justificada pela falta de recursos internos. Já os EUA mostram como o avanço na indústria fármaco da Cannabis, além de subsidiar a garantia do direito à saúde aos cidadãos, gera benefícios para a economia nacional. Por fim, o Estado israelense parece ser caminho plausível na realidade brasileira. Uma vez constatada as propriedades benéficas da maconha para tratamento de determinadas doenças, o uso dos produtos à base das substâncias e a pesquisa clínica deve ser difundida. Porém, a liberação para utilização na medicina não é pressuposta para liberação do consumo recreativo, matéria essa diversa tanto no campo da biomedicina como para o campo jurídico.

\section{CONCLUSÃO}

Apresentado esse panorama objetivo e crítico, reflete-se sobre os dilemas transcorridos e de soluções urgentes. Mais uma vez se pode verificar o quanto os princípios bioéticos e o próprio Biodireito se apresentam como meios necessários para se tratar assuntos como este.

À luz do princípio da autonomia, consegue-se vislumbrar o quanto a restrição do uso medicinal da Cannabis afeta diretamente o direito de escolha sobre qual o melhor designo e tratamento o paciente entende ser bom para sua vida. Tal princípio não é uma possibilidade de

65 RASMUSSEN, Bruna. 0 que mudou nos países que decidiram regulamentar a maconha medicinal. 2016. Disponível em: <http://www.hypeness.com.br/2015/07/quais-foram-os-impactos-douso-medicinal-da-maconha-nos-paises-que-o-legalizaram/>. Acesso em: 21 ago. 2017. 
liberdade absoluta para que o indivíduo tome medidas por si só. 0 que se suscita é como a autonomia, ou seja, a possibilidade de reger-se por suas regras, após um consentimento livre e esclarecido, é afetada pela restrição aqui exposta. Muitas das patologias descritas se encontram atualmente sem um tratamento de cura sendo necessário que medidas paliativas supram os seus sintomas. Por esses motivos, a possibilidade que emerge dos medicamentos à base da maconha favorece, em grande parte dos casos, uma vida digna e menos gravosa aos que estão no entorno.

Nesse sentido, o direito do paciente de escolher seu medicamento é violado em dois pontos centrais. Diante da tomada de decisão sobre os métodos de terapêuticos que irá optar para combater a doença, o enfermo que se enquadra nos tratamentos à base da maconha tem sua escolha interna comprometida, pois o status de entorpecente da Cannabis gera um sentimento negativo para o uso. Passada essa questão, o indivíduo tem sua vontade desiludida pela dificuldade de se tratar com medicamentos advindos da planta, uma vez que o acesso a esses fármacos ou vias terapêuticas sofrem sanção desmedida por parte do Estado.

Ao se observar o pequeno esterço sobre os avanços medicinais elencados nas linhas anteriores, observa-se que mesmo carecendo de estabilização, o tratamento à base da maconha tem se demonstrado ter eficácia em determinadas enfermidades que não possuem outro tipo de intervenção. Dessa maneira, mesmo comprovada a eficácia de certos fármacos provenientes da Cannabis os pacientes brasileiros são impedidos de adquiri-los por conta da letargia do poder legislativo, já que não avança nas discussões sobre o tema de forma operante, não viabilizando que as agências reguladoras proponham soluções para a fiscalização e o funcionamento do comércio em território nacional.

Os casos supracitados exemplificam a discussão proposta no presente trabalho. Mesmo havendo casos de possibilidade de uso das propriedades terapêuticas da Cannabis, a burocracia e entraves administrativos levam a situações quase desesperadoras. Os casos de Anny e de Clarian demonstram como é necessária a mobilização judicial intensa, causando transtornos e desgastes aos entes envolvidos. Além disso, a impossibilidade de uma pesquisa mais intensa para fins terapêuticos do uso da maconha, trava a disseminação de informações para uma produção nacional de medicamentos, impedindo assim, que maiores números de pacientes tenham acesso a esses produtos.

Analisando os exemplos de sistemas fora do Brasil de liberação da maconha, para uso recreativo ou medicinal, é possível visualizar diretrizes. Ao criar um órgão estatal específico para a matéria, o Uruguai aparentemente tratou a maconha com mais especificidade. No caso brasileiro, a concentração do controle da Cannabis medicinal sob a Anvisa, já mostrou que gera 
dificuldades para o cidadão e para a própria agência. Um avanço importante para o Brasil seria a instituição de um órgão específico para tratar a questão da maconha medicinal, desde os estudos para uma maior abertura, até numa possível difusão da utilização para fins terapêuticos. Outros nortes importantes estão na Argentina e Israel. No primeiro caso, há a possibilidade de regulamentação da importação de medicamentos enquanto não há definição sobre produção e pesquisa em âmbito nacional. Já no segundo exemplo, a matéria de uso recreativo e de uso medicinal são tratadas de formas distintas. Enquanto aquele é proibido, este tem sido difundido.

Obviamente, não se faz aqui nenhum tipo de incentivo ao uso de entorpecentes e nem se busca uma análise sobre descriminalização das drogas, tão pouco se afirma que a liberdade do paciente é irrestrita. Avalia-se que os estigmas sociais, somados à falta de agilidade legislativa e aos entraves burocráticos, afetam o direito de escolha do paciente. Direito esse pautado na possibilidade de uso de um tratamento com base científica considerável e já versada em outras nações.

Apesar da extensa discussão que emerge em diversas instâncias da sociedade brasileira sobre o uso medicinal da maconha, sua restrição ainda é prejudicial a grupos de enfermos. Mostra-se que nitidamente se faz necessário o avanço diante essa matéria pela sociedade, mas sobretudo pelo poder público. Portanto, é considerável o avanço que o judiciário e as agências estatais brasileiras têm dado ao assunto. Mas ainda não é suficiente. Há barreiras que impedem um acesso igualitário e possível a esse tratamento. Por isso, mesmo que polêmica, deve-se discutir cada dia mais tal problemática, para que, sanados esses conflitos, chegue-se a uma autonomia plena aos mais diversos pacientes.

\section{REFERÊNCIAS}

BARROSO, Luís Roberto. A Dignidade da Pessoa Humana no Direito Constitucional Contemporâneo: Natureza Jurídica, Conteúdos Mínimos e Critérios de Aplicação. Versão provisória para debate público. Mimeografado. [s.l], 2010. Disponível em <http:/ / luisrobertobarroso.com.br/wp-content/uploads/2016/06/Dignidade_textobase_11dez2010.pdf>. Acesso em: 14 de abr. 2018.

BARREIRO, Ramiro. Argentina aprueba el uso medicinal de la marihuana. 2017. Disponível em: <https://elpais.com/internacional/2017/03/30/actualidad/1490830376_425239.html>. Acesso em: 17 ago. 2017.

BRASIL. Agencia Nacional de Vigilância Sanitária. Resolução da Diretoria Colegiada - RDC N 66, de 18 de Março de 2016. Brasília, 2016. Publicada no D.O.U em 21.03.16. Disponível em: 
<http://portal.anvisa.gov.br/documents/33868/3233596/49+-+RDC+n $+66-2016 . p d f / 8 d 702 e 52-$ 45b9-4763-8e4c-1703740de9b8>. Acesso em: 21 jul. 2017.

BRASIL. Conselho Federal de Medicina. Resolução n 1.931. Publicada D.O.U em 24 de setembro de 2009, Seção I. Código de Ética Médico. Brasília, 2009. p. 90. Disponível em < https: / portal.cfm.org.br/images/stories/biblioteca/codigo\%20de\%20etica\%20medica.pdf> . Acesso em: 15 jun. 2017.

BRASIL. Senado Federal. Relatório Legislativo. Relator: Senador Cristovam Buarque. Sugestão ${ }^{\circ}$ 8. Brasília, 2014. Disponível em: <http://legis.senado.leg.br/sdleggetter/documento?dm=3624584\&disposition=inline>. Acesso em: 17 jul. 2017.

BRASIL. Supremo Tribunal Federal. Recurso Extraordinário $n^{\circ}$ 635.659. Julgamento Sobre Porte de Drogas Para Consumo Próprio: Voto oral Ministro Luiz Roberto Barroso. Brasília, 2017. Disponível em: < http://s.conjur.com.br/dl/leia-anotacoes-ministro-barroso-voto.pdf>. Acesso em: 15 jun. 2017.

BELTRÃO, Silvio Romero. Autonomia da vontade do paciente e capacidade para consentir: uma reflexão sobre a coação irresistível. Revista de Direito Sanitário, [s.l.], v. 17, n. 2, p.98-116, 25 out. 2016. Disponível em: <http://www.revistas.usp.br/rdisan/article/view/122316>. Acesso em: 13 abr. 2018.

CANCIAN, Natália. Justiça autoriza pais a plantar maconha em casa para tratar filhos. 2017. Disponível em: <http://www1.folha.uol.com.br/equilibrioesaude/2017/01/1850088-justicaautoriza-pais-a-plantar-maconha-em-casa-para-tratar-filhos.shtml>. Acesso em: 26 jun. 2017.

CANCIAN, Natália. Anvisa vai criar regras para cultivo de maconha medicinal. 2017. Disponível em: <http://www1.folha.uol.com.br/equilibrioesaude/2017/07/1903558-anvisa-vai-criar-regraspara-cultivo-de-maconha-medicinal.shtml>. Acesso em: 21 ago. 2017.

CARLINI, Elisaldo Araújo. A história da maconha no Brasil. Jornal Brasileiro de Psiquiatria, [s.l.], v. 55, n. 4, p.314-317, 2006. FapUNIFESP (SciELO). Disponível em: <http://dx.doi.org/10.1590/s0047-20852006000400008>. Acesso em: 26 jul. 2017.

CASTILLO, M. ${ }^{a}$ Mercedes Mingarro et al. Síndrome de Dravet. Revista Clínica de Medicina de Familia, [s.l.], v. 7, n. 2, p.134-136, jun. 2014. Instituto de Salud Carlos III/BNCS/SciELO Espana. Disponível em: <http://dx.doi.org/10.4321/s1699-695x2014000200008>. Acesso em: 26 jul. 2017.

CREMESP. Desinformação e má-fé permeiam o debate sobre liberação do canabidiol no Brasil. Jornal do Cremesp. [s.l], p. 16. jun. 2014. Disponível em: <http://www.cremesp.org.br/?siteAcao=Jornal\&id=1898>. Acesso em: 08 ago. 2017.

COHEN, Claudio; MARCOLINO, José Álvaro Marques. Relação Médico-Paciênte. In: SEGRE, Marco; COHEN, Claudio. Bioética. 2. ed. São Paulo: Editora da Universidade de São Paulo, 1999. Cap. 5. p. 51-62.

DINIZ, Débora; GUILHEM, Dirce. O que é Bioética. São Paulo: Brasiliense, 2002.

DINIZ, Maria Helena. 0 estado atual do biodireito. 2. ed. São Paulo: Saraiva, 2002.

FABRIZ, Daury Cesar. Bioética e direitos fundamentais. Belo Horizonte: Mandamentos, 2003. 
FERRARI, Dércio Fernando Moraes; NERES, Geraldo Magella. Políticas públicas no uruguai em tempos de mujica: o impacto da legalização do aborto e da maconha sobre a mídia digital brasileira. Tempo da Ciência, [s.l], v. 22, n. 43, p.55-62, jan/jul. 2015. Disponível em: <http://e-revista.unioeste.br/index.php/tempodaciencia/article/view/12640>. Acesso em: 21 ago. 2017.

FIGUEIREDO, Emílio Nabas; OTERO, Lorena. Entre a criminalidade e a constitucionalidade: o cultivo e produção de cannabis para fins terapêuticos. Boletim: Publicação do Instituto Brasileiro de Ciências Criminais, [s.l], n. 286, p.22-23, set. 2016. Disponível em: < https://www.ibccrim.org.br/boletim_artigo/5834-Entre-a-criminalidade-e-aconstitucionalidade-o-cultivo-e-producao-de-cannabis-para-fins-terapeuticos>. Acesso em: 20 jul. 2017.

GOMES, Luiz Flávio; SOUZA, Áurea Maria Ferraz. Tráfico ou usuário de droga: depende do caso concreto. 2010. Disponível em: <https: //lfg.jusbrasil.com.br/noticias/2499711/artigos-do-proflfg-trafico-ou-usuario-de-droga-depende-do-caso-concreto>. Acesso em: 20 jul. 2017.

HONÓRIO, Káthia Maria; ARROIO, Agnaldo; SILVA, Albérico Borges Ferreira da. Aspectos terapêuticos de compostos da planta Cannabis sativa. Química Nova, [s.l.], v. 29, n. 2, p.318325, abr. 2006. FapUNIFESP (SciELO). Disponível em: <http://dx.doi.org/10.1590/s010040422006000200024>. Acesso em: 20 jul. 2017

KANT, Immanuel. Fundamentação da metafísica dos costumes. Lisboa: 70 Edições, 2007.

LIMA FILHO, Francisco de Assis. Todo vagabundo é maconheiro, mas nem todo maconheiro é vagabundo": Um estudo com consumidores estáveis de maconha. 2010. 151 f. Dissertação (Mestrado) - Curso de Psicologia, Universidade Federal do Espírito Santo, Vitória, 2010.

LUCENA, Willian Felipe. As políticas de legalização da maconha: Uma discussão baseada em evidências. 2012. 27 f. Monografia (Especialização) - Curso de Especialização em Dependência Química, Universidade Federal de São Paulo, São Paulo, 2012. Disponível em:

<http://www.uniad.org.br/images/stories/TCCS/MONOGRAFIA_ESPECIALIZACAO-5.pdf>. Acesso em: 21 ago. 2017.

MATOS, Alexandre. Projetos na UFRJ e Fiocruz para desenvolver medicamento à base de maconha. 2017. Disponível em: <http://www.far.fiocruz.br/2017/01/projetos-na-ufrj-e-fiocruzpara-desenvolver-medicamento-a-base-de-maconha/>. Acesso em: 26 jul. 2017.

MORAES, Ana Luísa. Substâncias da maconha ajudariam na luta contra o câncer. 2017. Disponível em: <http://saude.abril.com.br/medicina/substancias-da-maconha-ajudariam-naluta-contra-o-cancer/>. Acesso em: 20 jul. 2017.

MUÑOZ, Daniel Romero; FORTES, Paulo Antonio Carvalho. O Princípio da Autonomia e o Consentimento Livre e Esclarecido. In: COSTA, Sérgio Ibiapina Ferreira; GARRAFA, Volnei; OSELKA, Gabriel. Iniciação à Bioética. [s.l]: Conselho Federal de Medicina, 1998. p. 53-70. Disponível em: <http://portal.cfm.org.br/images/stories/biblioteca/iniciao biotica.pdf >. Acesso em: 15 jul. 2017.

PAVÓN, Carmen Osorio. Uso terapéutico del cannabis. 2016. 25 f. TCC (Graduação) - Curso de Enfermagem, Universidad de Cantabria, Cantabria, 2016. Disponível em: < 
http://www.pensamientopenal.com.ar/miscelaneas/44468-uso-terapeutico-del-cannabiscarmen-osorio-pavon>. Acesso em: 15 jul. 2017.

QUEVEDO, Lenin de Ramon. Cannabis y medicina tradicional: libertad, sociabilidad y subsidiariedad de este tipo de fitoterapia. Vida y Ética, [s.l], v. 1, n. 16, p.55-72, jun. 2015. Disponível em: <http://bibliotecadigital.uca.edu.ar/repositorio/revistas/cannabis-medicinatradiconal-fitoterapia.pdf>. Acesso em: 10 ago. 2017.

RASMUSSEN, Bruna. 0 que mudou nos países que decidiram regulamentar a maconha medicinal. 2016. Disponível em: <http://www.hypeness.com.br/2015/07/quais-foram-osimpactos-do-uso-medicinal-da-maconha-nos-paises-que-o-legalizaram/>. Acesso em: 21 ago. 2017.

RIBEIRO, José António Curral. A Cannabis e suas aplicações terapêuticas. 2014. 51 f. Dissertação (Mestrado) - Curso de Ciências Farmacêuticas, Faculdade de Ciências da Saúde, Universidade Fernando Pessoa, Porto, 2014. Disponível em: <http://bdigital.ufp.pt/bitstream/10284/4828/1/PPG_20204.pdf>. Acesso em: 20 jul. 2017.

REDAÇÃO. Associação ganha direito de fazer cultivo medicinal de maconha. 2017. Disponível em: <http://www.jornaldaparaiba.com.br/vida_urbana/noticia/183989_associacao-ganhadireito-de-fazer-cultivo-medicinal-de-maconha>. Acesso em: 26 jul. 2017.

ROSA, Gabriel Pesca da. Cannanis medicinal: Entre os saberes das ciências sociais e biomedicina. 2016. 47 f. TCC (Graduação) - Curso de Ciências Sociais, Universidade Federal de Santa Catarina, Florianópolis, 2016. Disponível em: <https://repositorio.ufsc.br/handle/123456789/166294>. Acesso em: 21 ago. 2017.

SÁ, Maria de Fátima Freire de; NAVES, Bruno Torquato de Oliveira. Manual de Biodireito. Belo Horizonte: del Rey, 2011.

SANLLEHÍ, Josep. A vueltas con el principio de autonomía. In: CASADO, María. Estudios de Bioética y Derecho. Valencia: Tirant Lo Blanch, 2000. p. 101-112.

SARLET, Ingo Wolfgang. A eficácia dos Direitos Fundamentais. Porto Alegre: Livraria do Advogado, 1998.

SILVA, Felipe Figueiredo Gonçalves da. Não compre, plante?: Tipificação penal do cultivo de Cannabis pelo Tribunal de Justiça de São Paulo. Boletim: Publicação do Instituto Brasileiro de Ciências Criminais, [s.l], n. 286, p.20-22, set. 2016. Disponível em:

<http://www.ibccrim.org.br/site/boletim/pdfs/Boletim286.pdf> Acesso em: 20 jul. 2017.

SILVA, José Edivaldo da; SILVA, Samuel Pereira da. Descriminalização ou legalização do uso Da maconha? E os projetos de lei sobre a Maconha descriminalizar ou legalizar? Cadernos de Graduação, [s.l], v. 3, n. 1, p.21-34, jul. 2017. Disponível em:

<https://periodicos.set.edu.br/index.php/facipehumanas/article/view/3721> Acesso em: 10 ago. 2017.

STELLA, Rita. USP terá primeiro centro de pesquisa em canabidiol do País. 2017. Disponível em: <http: / / jornal.usp.br/universidade/usp-tera-primeiro-centro-de-pesquisa-em-canabidioldo-pais/>. Acesso em: 27 jul. 2017. 
ONU. Organização das Nações Unidas. Código de Nuremberg. 1947. Disponível em:

<http://www.fcm.unicamp.br/fcm/sites/default/files/codigo_de_nuremberg.pdf>. Acesso em: 15 jul. 2017.

USP. Síndrome de Rett. [S.d]. Disponível em: <http://www.genoma.ib.usp.br/pt$\mathrm{br} /$ servicos/consultas-e-testes-geneticos/doencas-atendidas/sindrome-de-rett>. Acesso em: 24 jul. 2017.

ZANATTO, Rafael Morato. Maconha: Weltanschauung em trans - form - ação! Boletim Maconhabrás. [s.l], p. 6-7. dez. 2015. Disponível em: <http://www.cebrid.com.br/wpcontent/uploads/2016/01/Boletim-Maconhabrás-No.-05.pdf>. Acesso em: 21 ago. 2017.

Recebido em: 10.10.2017 / Revisões requeridas em: 28.02.2018 / Aprovado em: 09.07.2018 / Publicado em: 30.08.2018

\section{COMO FAZER A REFERÊNCIA DO ARTIGO (ABNT):}

ZAGANELLI, Margareth Vetis; CORREIA, João Victor Gomes. A restrição do uso medicinal da cannabis sativa face ao princípio da autonomia da vontade. Revista Eletrônica do Curso de Direito da UFSM, Santa Maria, RS, v. 13, n. 2, p. 610-639, ago. 2018. ISSN 1981-3694. Disponível em: <https://periodicos.ufsm.br/revistadireito/article/view/29501>. Acesso em: dia mês. ano. doi: http://dx.doi.org/10.5902/1981369429501. 